\title{
Endobiliary radiofrequency ablation for ingrowth occlusion after bilateral metal stent placement in patients with malignant hilar biliary obstruction
}
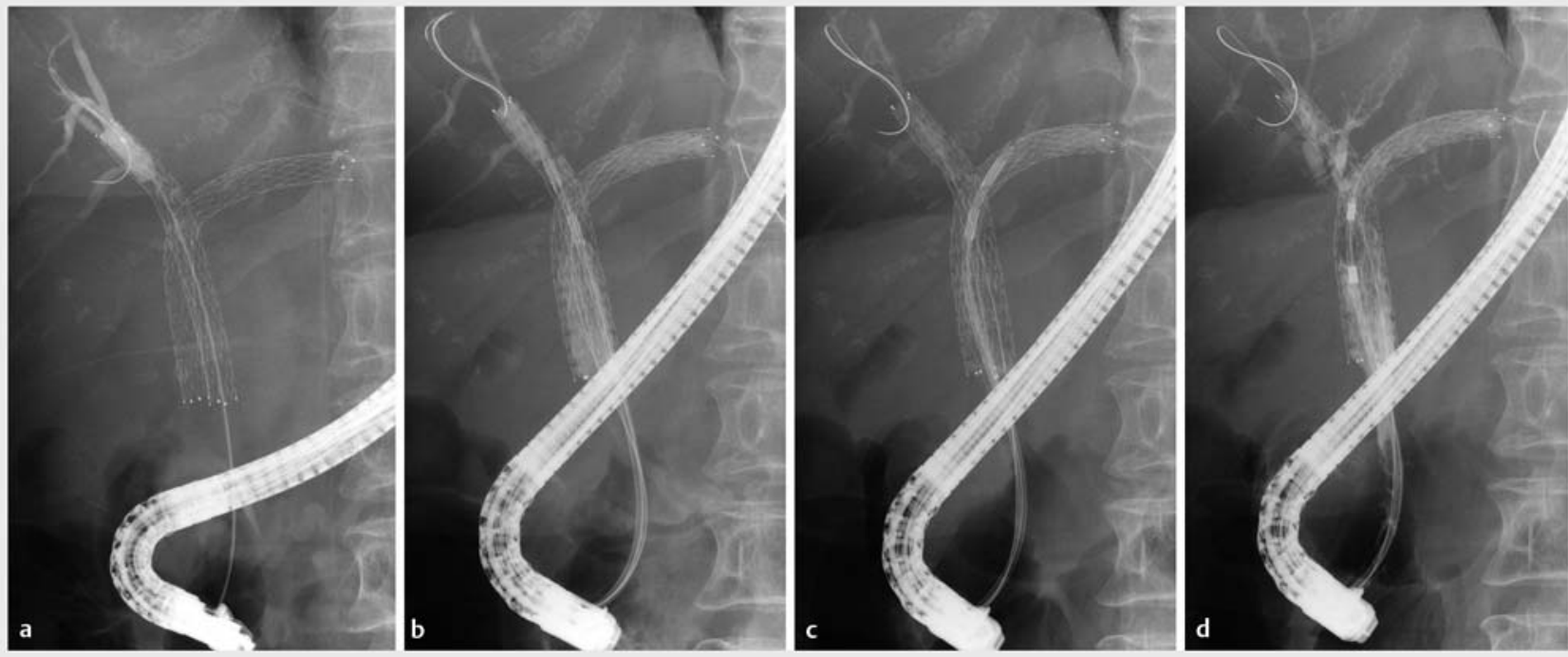

- Fig. 1 a Cholangiography revealed strictures within previously placed metal stents in the hilar region due to ingrowth. b Radiofrequency ablation was performed of the ingrowth region within the right metal stent. $\mathbf{c}$ Radiofrequency ablation was performed of the ingrowth region within the left metal stent. $\mathbf{d}$ After the ablation, tissue debris was retrieved with a balloon catheter, and the stricture improved.

Endobiliary radiofrequency ablation (RFA) can prolong the patency of bilateral metal stents (MS) in patients with malignant hilar biliary obstruction [1]. In addition, RFA is a potential treatment option for stent occlusion caused by ingrowth after MS placement [2]. However, there is no evidence of the feasibility of RFA in treating ingrowth after bilateral placement and the safety of repeated RFA remains unknown. Here, we describe a patient who underwent RFA reintervention for ingrowth occlusion after bilateral stent-by-stent (SBS) MS placement with RFA.

An 84-year-old woman with unresectable cholangiocarcinoma had undergone bilateral SBS placement using an uncovered MS (ZeoStent V, Zeon Medical, Tokyo, Japan), following RFA to the left and right hepatic duct strictures using Habib EndoHPB Catheter (Boston Scientific, Marlborough, Massachusetts, United States) and VIO300D generator (ERBE Elektromedizin $\mathrm{GmbH}$, Tubingen, Ger-

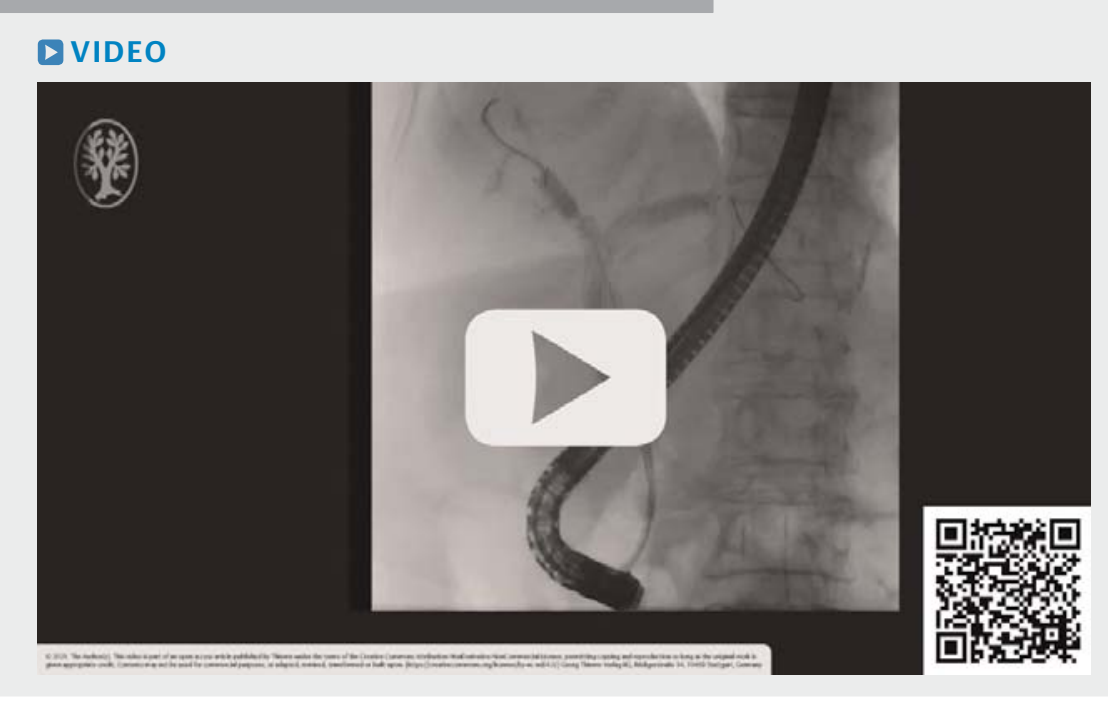

- Video 1 Endobiliary radiofrequency ablation for ingrowth occlusion after bilateral stent-by-stent placement in a patient with malignant hilar biliary obstruction.

many). Six months after the procedure, obstructive jaundice recurred due to stent occlusion; thus, we performed en- doscopic reintervention. After biliary cannulation, two guidewires were advanced into the left and right intrahepa- 
tic bile ducts through each MS. A cholangioscope (SpyGlass DS; Boston Scientific) was subsequently inserted over the guidewire, and the cause of occlusion was determined to be an ingrowth in the hilar region. We then performed RFA to the ingrowth within each MS for $90 \mathrm{~s}$ at $7 \mathrm{~W}$. Tissue debris was retrieved using a balloon catheter, and the stent lumen was successfully recanalized ( and $>$ Video 1 ). The patient's symptoms improved without adverse events, and the stents were patent during the follow-up period.

\section{Conclusions}

The management of stent occlusion after bilateral MS placement has not been established. Endobiliary RFA may be a useful option when treating ingrowth occlusion, especially after SBS placement.

\section{Competing interests}

Dr. Inoue received honoraria from Boston Scientific Japan and Japan Lifeline Co., Ltd, outside the submitted work.

The other authors disclose no financial relationships relevant to this publication.

The authors

Tadahisa Inoue, Rena Kitano, Masashi Yoneda Department of Gastroenterology, Aichi Medical University, Aichi, Japan

\section{Corresponding author}

\section{Tadahisa Inoue, MD, PhD}

Department of Gastroenterology, Aichi Medical University, Yazakokarimata, Nagakute, Aichi 480-1195, Japan

Fax: +81561633208

tinoue-tag@umin.ac.jp

\section{References}

[1] Inoue T, Ibusuki M, Kitano R et al. Endobiliary radiofrequency ablation combined with bilateral metal stent placement for malignant hilar biliary obstruction. Endoscopy 2020; 52: 595-599

[2] Kadayifci A, Atar M, Forcione DG et al. Radiofrequency ablation for the management of occluded biliary metal stents. Endoscopy 2016; 48: 1096-1101

\section{Bibliography}

Endosc Int Open 2021; 09: E907-E908

DOI 10.1055/a-1396-4182

ISSN 2364-3722

(c) 2021. The Author(s).

This is an open access article published by Thieme under the terms of the Creative Commons Attribution-NonDerivativeNonCommercial License, permitting copying and reproduction so long as the original work is given appropriate credit. Contents may not be used for commercial purposes, or adapted, remixed, transformed or built upon. (https:// creativecommons.org/licenses/by-nc-nd/4.0/)

Georg Thieme Verlag KG, Rüdigerstraße 14, 70469 Stuttgart, Germany 